\title{
Characterization of an ionic liquid-tolerant $\beta$-xylosidase from a marine-derived fungal endophyte
}

\begin{tabular}{|c|c|}
\hline Journal: & Biochemistry and Cell Biology \\
\hline Manuscript ID & bcb-2017-0053.R2 \\
\hline Manuscript Type: & Note \\
\hline Date Submitted by the Author: & 16-May-2017 \\
\hline Complete List of Authors: & $\begin{array}{l}\text { Sengupta, Anindita; The Ohio State University, Chemistry \& Biochemistry } \\
\text { Zabala, Angela; The Ohio State University, Chemistry \& Biochemistry } \\
\text { Tan, Si Yu; The Ohio State University, Chemistry \& Biochemistry } \\
\text { Broadstock, Arthur; The Ohio State University, Chemistry \& Biochemistry } \\
\text { Suryanarayanan, T; VINSTROM } \\
\text { Gopalan, Venkat; The Ohio State University, Chemistry \& Biochemistry }\end{array}$ \\
\hline $\begin{array}{r}\text { Is the invited manuscript for } \\
\text { consideration in a Special } \\
\text { Issue? : }\end{array}$ & N/A \\
\hline Keyword: & Fungi, Xylosidase, Ethylmethyl-imidazolium-based ionic liquids \\
\hline
\end{tabular}




\title{
Characterization of an ionic liquid-tolerant $\beta$-xylosidase from a marine-derived fungal endophyte
}

\author{
Anindita Sengupta, ${ }^{a}$ Angela Zabala, ${ }^{\text {a,\# }}$ Si Yu Tan,,${ }^{\text {a,\# }}$ \\ Arthur Broadstock, ${ }^{\mathrm{a}, \#}$ Trichur S Suryanarayanan ${ }^{\mathrm{b}}$ and Venkat Gopalan ${ }^{\mathrm{a}, *}$ \\ aDepartment of Chemistry \& Biochemistry \\ The Ohio State University, Columbus, OH 43210, USA \\ bivekananda Institute of Tropical Mycology (VINSTROM), \\ Ramakrishna Mission Vidyapith, Chennai 600004, INDIA \\ \# These authors contributed equally to this work.
}

* Corresponding author. Email: gopalan.5@osu.edu; Fax: 614-292-6773; Tel: 614-292-1332 


\section{ABSTRACT}

lonic liquids (ILs) are used in lignocellulosic biomass (LCB) pretreatment due to their ability to disrupt the extensive hydrogen-bonding network in cellulose and hemicellulose, and thereby decrease LCB recalcitrance to subsequent enzymatic degradation. However, this approach necessitates development of a cellulases and hemicellulases that can tolerate $\sim 20 \%(\mathrm{w} / \mathrm{v}) \mathrm{IL}$, an amount that either co-precipitates with the sugar polymers after the initial pretreatment or is typically used in single-pot biomass deconstructions. By investigating the secretomes from four marine-derived fungal endophytes, we identified a Trichoderma harzianum-derived $\beta$-xylosidase as the most promising in terms of tolerating 1-ethyl-3-methylimidazolium-dimethyl phosphate (EMIM-DMP), an IL. When tested with p-nitrophenyl- $\beta$-D-xyloside, this extracellular xylosidase retained $\sim 50 \%$ activity even in $1.2 \mathrm{M}(20 \% \mathrm{w} / \mathrm{v})$ EMIM-DMP after a $48-\mathrm{h}$ incubation. When tested on the natural substrate xylobiose, there was $\sim 85 \%$ of the initial activity in $1.2 \mathrm{M}$ EMIM-DMP after a 9-h incubation and $\sim 80 \%$ after a $48-\mathrm{h}$ incubation. Despite previous findings associating thermostability and IL tolerance, our findings related to the mesophilic T. harzianum $\beta$-xylosidase(s) emphasize the need to include the marine habitat in the bioprospecting dragnet for identification of new ILtolerant LCB-degrading enzymes.

Keywords: Ethylmethyl-imidazolium-based ionic liquids, fungi, $\beta$-xylosidase 


\section{INTRODUCTION}

The deconstruction of lignocellulosic biomass (LCB) to monosaccharides is a prerequisite for microbial fermentation of biomass to liquid fuels or chemicals. However, LCB is refractory to degradation due to its complex structure [cellulose (40-50\%), hemicellulose (25-35\%) and lignin (10-20\%)]. Harsh physical/chemical pre-treatment of LCB must therefore precede enzymatic depolymerization of cellulose and hemicellulose (Himmel et al. 2007; Wilson 2009), but these high temperature $\left(>150^{\circ} \mathrm{C}\right.$ ) or highly acidic pre-treatments contribute to increased processing costs and to environmental concerns. An emerging chemical pre-treatment alternative entails the use of non-volatile, ionic liquids (ILs) to dissolve LCB and enhance accessibility of the sugar polymers to enzymatic breakdown (Liu et al. 2012; Peleteiro et al. 2015; Wahlstrom and Suurnakki 2015). Despite the proven ability of ILs to decrease biomass recalcitrance and increase the saccharification efficiency of glycohydrolases (Dadi et al. 2006; Swatloski et al. 2002), the wide use of ILs requires overcoming various challenges (Liu et al. 2012; Peleteiro et al. 2015; Wahlstrom and Suurnakki 2015), a motivation for this study.

ILs are composed of a large organic cation and an organic/inorganic anion (e.g., 1ethyl-3-methylimidazolium dimethylphosphate (EMIM-DMP, Scheme 1), and have melting points $<100^{\circ} \mathrm{C}$. Imidazolium-based ILs exploit ionic, $\pi-\pi$ and hydrogen bonding interactions to disrupt the extensive hydrogen-bonding network in (hemi)cellulose and decrease LCB recalcitrance to degradation (Liu et al. 2012; Peleteiro et al. 2015; Wahlstrom and Suurnakki 2015). However, ILs also denature and inactivate many of the commercial cellulases used for saccharification of pre-treated biomass (Ilmberger et al. 2013; Turner et al. 2003; Wahlstrom and Suurnakki 2015). This problem has been addressed using different approaches. First, if $100 \%(\mathrm{w} / \mathrm{v}) \mathrm{IL}$ is used during pretreatment, copious washing with water prevents adverse effects on subsequent saccharification and fermentation; cost and waste considerations disfavor this route (Liu et al. 2012; Peleteiro et al. 2015; Wahlstrom and Suurnakki 2015). Second, after LCB dissolution by an IL, cellulose and hemicellulose can be precipitated with a miscible anti-solvent like ethanol and recovered in an amorphous and porous form (Nakamura et 
al. 2010; Vancov et al. 2012). With this option, at least $15-20 \%$ residual, entrapped IL co-precipitates with the sugar polymers. Last, effective biomass pre-treatment with IL:water mixtures containing 10-20\% (w/v) IL has led to design of single-pot strategies for pre-treatment and enzymatic hydrolysis (Kamiya et al. 2008; Park et al. 2012; Shi et al. 2013). This approach eliminates washing, and culminates in recovery of ILs and sugars.

Despite the higher water solubility of many hemicelluloses compared to cellulose, xylan (the major constituent of hemi-cellulose and the second most abundant polysaccharide in nature) and cellulose are both recovered in the anti-solvent precipitate; for example, ethanol recovers $96 \%$ of cellulose and $80 \%$ of xylan liquefied using EMIM-chloride (Nakamura et al. 2010). IL/co-solvent systems have also been optimized for the selective recovery of hemicellulose and cellulose from wood pulp (Froschauer et al. 2013), reflecting the value of ILs for LCB fractionation and subsequent utilization of individual components. With all these approaches, however, IL-tolerant cellulases and hemi-cellulases are needed for saccharification. Toward this goal, endo-glucanases, cellobiosidases and $\beta$-glucosidases (the trio of cellulolytic enzymes) that tolerate up to $40 \%$ (v/v) IL have been identified from thermophilic/halophilic bacteria and archaea (Datta et al. 2010; Gladden et al. 2011; Ilmberger et al. 2012; Park et al. 2012; Zhang et al. 2011). We focused our efforts to develop the complementary IL-tolerant hemi-cellulase repertoire, in part because the hemicellulose physical barrier impedes cellulase-mediated depolymerization of cellulose to glucose (Qing and Wyman 2011; Qing et al. 2010).

For bioprospecting, we directed our attention to endophytic fungi, which infect and survive in plant tissues including marine algae without causing any apparent disease in the host. These fungi have leveraged millions of years of co-evolution with plants to dominate the plant microbiome and built an impressive catalytic inventory that enables them to function as primary degraders of LCB (Cord-Landwehr et al. 2016; Correa et al. 2014; Prakash et al. 2015; Robl et al. 2013; Suryanarayanan et al. 2012). Fungal enzymes, due to post-translational modifications, are also expected to better withstand 
physical/chemical stresses (Beckham et al. 2012). Moreover, since some seagrasses contain up to $40 \%$ xylan as part of their LCB (Davies et al. 2007), we hypothesized that their resident endophytic fungi may have evolved efficient mechanisms for xylan degradation. Our studies in this regard uncovered a mesophilic $\beta$-xylosidase that is remarkably tolerant to ILs.

\section{MATERIALS \& METHODS}

\section{Reagents}

All reagents and chemicals used in this study were analytical or molecular biology grade and obtained commercially. EMIM-DMP, EMIM-chloride (EMIM-Cl) and EMIM-acetate (EMIM-Ac) were purchased from Sigma Chemical Co. (St. Louis, Missouri, USA), Acros Organics (Fairlawn, New Jersey, USA) and Ionic Liquid Technologies (Tuscaloosa, Alabama, USA), respectively; these ionic liquids were $99 \%$ pure. While xylobiose and xylotriose (95\% purity) were purchased from Megazyme International Ireland, Limited (Bray, County Wicklow, IRELAND), xylose (99.9\% purity) and 4-methylumbelliferyl- $\beta$-Dxyloside (4-MU- $\beta-D-X y l)$ were obtained from Sigma Chemical Co. (St. Louis, Missouri, USA). Para-nitrophenyl- $\beta$-D-xyloside (pNP- $\beta$-D-Xyl) and 3,5-dinitrosalicylic acid (DNS) were purchased from Gold Biotechnology (St. Louis, Missouri, USA) and MCB Chemicals (Gibbstown, New Jersey, USA), respectively.

\section{Preparation of crude secretomes}

The endophyte secretomes were prepared essentially as described elsewhere (Thirunavukkarasu et al. 2015). Trichoderma harzianum, Curvularia tuberculata, Gonatophragmium mori and Aspergillus terreus were grown in birch wood xylan

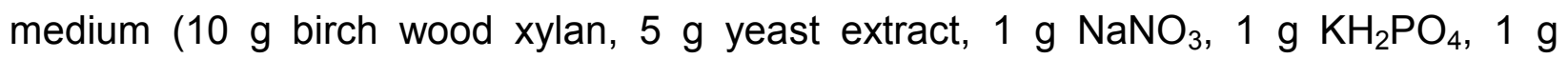
peptone, $0.3 \mathrm{~g} \mathrm{MgSO}_{4} \cdot 7 \mathrm{H}_{2} \mathrm{O}$ ) for 5 days at $31^{\circ} \mathrm{C}$ in an orbital shaker (120 rpm). To obtain the secretome, the culture fluid was passed through a Whatman \#1 filter paper and the filtrate centrifuged at $9,600 \mathrm{~g}$ for $20 \mathrm{~min}$ at $4^{\circ} \mathrm{C}$. The supernatant thus obtained was dialyzed extensively against water with three changes over $16-18 \mathrm{~h}$ at $4^{\circ} \mathrm{C}$, and lyophilized. Prior to enzyme assays, $\sim 20 \mathrm{mg}$ of the lyophilized samples was re- 
suspended in $300 \mu \mathrm{l}$ 1X phosphate-buffered saline (PBS) and centrifuged at $16,000 \mathrm{~g}$ for $10 \mathrm{~min}$ to remove insoluble particulate material. The protein amount in the resulting supernatant was estimated using the Bradford assay, with bovine serum albumin (BSA) serving as the standard.

\section{Enzyme assays}

Extracellular xylosidase activity was determined either by measuring p-nitrophenol formed through cleavage of pNP- $\beta-D-X y l$ or by measuring DNS reactivity of xylose (a reducing sugar) generated from cleavage of xylobiose/xylotriose as substrate. While the protocols used are essentially as described before (Thirunavukkarasu et al. 2015), some modifications are detailed below.

All assays were performed at $37^{\circ} \mathrm{C}$ in a final concentration of $33 \mathrm{mM}$ sodium acetate (pH 5.2). For pNP-based assays, either $3.33 \mathrm{mM}$ or $10 \mathrm{mM}$ pNP- $\beta-D-X y l$ was used for assays of $\leq 2 \mathrm{~h}$ or $>2 \mathrm{~h}$, respectively. pNP- $\beta$-D-Xyl was pre-incubated at $37^{\circ} \mathrm{C}$ for $7 \mathrm{~min}$ in a volume of $486 \mu \mathrm{l}$, and the reaction initiated by adding a defined amount of secretome $(\sim 8 \mu \mathrm{g}$ protein re-suspended in $14 \mu \mathrm{l}$ PBS) that had been pre-incubated separately for $7 \mathrm{~min}$ at $37^{\circ} \mathrm{C}$; for the secretome obtained from $T$. harzianum grown in the absence of $\mathrm{NaCl}$, three-fold more protein was used to compensate for the lower specific activity. To determine the effects of $\mathrm{NaCl}$ or ILs on xylosidase activity, a defined concentration of $\mathrm{NaCl} / \mathrm{LL}$ was added to the substrate and the $\mathrm{pH}$ was readjusted to 5.2 before pre-incubation at $37^{\circ} \mathrm{C}$. In all instances, $54 \mu \mathrm{l}$ aliquots were withdrawn at different time points and the reaction was terminated by the addition of $54 \mu \mathrm{l}$ of $1 \mathrm{M}$ sodium carbonate. The amount of $p$-nitrophenol formed was then determined by measuring the absorbance at $405 \mathrm{~nm}\left(\mathrm{Abs}_{405}\right)$ using a M1000 PRO (Tecan) plate reader. For each assay, the reaction mixture containing the secretome, substrate and buffer but that had not been subjected to incubation at $37^{\circ} \mathrm{C}$ was used as a background control. Any pNP generated from possible breakdown of pNP- $\beta$-D-Xyl and/or adventitious $\mathrm{Abs}_{405}$ by the secretome was accounted for by subtracting the $A b_{405}$ value of the reaction mixture 
that had been subjected only to the pre-incubation step. We also determined that there was no measurable release of pNP from uncatalyzed hydrolysis of pNP- $\beta$-D-Xyl even over a incubation of $48 \mathrm{~h}$ at $\mathrm{pH} 5.2$ (data not shown).

To study the $\beta$-xylosidase activities on xylobiose, DNS-based assays were performed. Ten $\mathrm{mM}$ xylobiose was pre-incubated at $37^{\circ} \mathrm{C}$ for $7 \mathrm{~min}$ in a volume of 198 $\mu \mathrm{l}$, and the reaction initiated by adding a defined amount of secretome ( $\sim 3.6 \mu \mathrm{g}$ protein re-suspended in $2 \mu \mathrm{l}$ PBS) that had been pre-incubated separately for $7 \mathrm{~min}$ at $37^{\circ} \mathrm{C}$. At defined time points, $30 \mu \mathrm{l}$ aliquots were withdrawn and mixed with $30 \mu \mathrm{l} 1 \%$ (w/v) DNS prior to boiling for $10 \mathrm{~min}$. These reaction mixtures were cooled to $22^{\circ} \mathrm{C}$, and their $\mathrm{Abs}_{540}$ values were measured using an M1000 PRO (Tecan) plate reader. Blanks entailed mixing of pre-incubated secretome and substrate, followed by addition of $1 \%$ $(w / v)$ DNS and immediate boiling.

Because we observed increased reactivity of reducing sugars in the presence of ILs, we generated standard curves for xylose, xylobiose or xylotriose in the presence of 0.6 or 0.9 or 1.2 M EMIM-DMP. Regardless of the mono-, di- or tri-saccharide used, there was an increased $A b_{540}$ of 1.25-, 1.36- or 1.51-fold with $0.6,0.9$ or $1.2 \mathrm{M} \mathrm{EMIM-}$ DMP, respectively. Thus, to determine the xylose released in assays containing EMIMDMP, we used the standard curve generated with the specified amount of EMIM-DMP.

One unit corresponds to the amount of enzyme that produces $1 \mu \mathrm{mol}$ of product per minute and specific activity was expressed as enzyme units per mg soluble protein. Linear regression (Excel) analysis of the product formed was used to calculate the initial velocity as a function of time $\left(0.96<r^{2}<0.99\right)$. Mean and standard deviation values were calculated from at least three independent assays.

We refer to the $T$. harzianum secretome obtained by growing the fungus in a medium without or with $1.5 \%(\mathrm{w} / \mathrm{v}) \mathrm{NaCl}$ as Tha S- or Tha $\mathrm{S}+$, respectively. The specific activities of Tha S- and Tha S+ are to 0.0021 and $0.016 \mu \mathrm{moles} / \mathrm{min} / \mathrm{mg}$ of protein, respectively, using pNP-Xyl as the substrate (reference values for normalization in Figs. 
1, 2 and 3). The specific activity of Tha $\mathrm{S}+$ is $0.035 \mu \mathrm{moles} / \mathrm{min} / \mathrm{mg}$ of protein using xylobiose as the substrate.

\section{Zymogram analysis of $\beta$-xylosidase(s) in the T. harzianum secretome}

Fifteen $\mu \mathrm{l}$ each of the Tha S- and Tha S+ crude secretomes re-suspended in 1X PBS $(\sim 40 \mu \mathrm{g})$ were mixed individually with $7 \mu \mathrm{l} 62.5 \mathrm{mM}$ Tris-HCl $(\mathrm{pH} 6.8), 25 \%(\mathrm{v} / \mathrm{v})$ glycerol, $1 \%(\mathrm{w} / \mathrm{v})$ bromophenol blue, and the entire amount loaded (without any additional treatment) onto a $12 \%(\mathrm{w} / \mathrm{v})$ polyacrylamide gel. Following electrophoresis, the gel was washed twice with distilled water (5 min each) and incubated in $33 \mathrm{mM}$ sodium acetate $\left(\mathrm{pH} \mathrm{5.5)}\right.$ for $10 \mathrm{~min}$ at $22^{\circ} \mathrm{C}$. To detect the $\beta$-xylosidase activity, the gel was incubated in the presence of $2 \mathrm{mM} 4-M U-\beta-D-X y l$, which was prepared in $33 \mathrm{mM}$ sodium acetate $(\mathrm{pH} 5.5)$. After incubation for $20 \mathrm{~min}$ at $50^{\circ} \mathrm{C}$ in the dark, the polypeptides with $\beta$-xylosidase activity were visualized using a $366-\mathrm{nm}$ transilluminator (Fotodyne, Inc., Hartland, WI).

\section{RESULTS}

\section{Rationale}

We recently reported that select marine-derived fungi (MDF) isolated as endophytes from marine algae and seagrasses produce xylanases and xylosidases (Thirunavukkarasu et al. 2015). These MDF differ from obligate marine fungi in not requiring an exclusive marine environment to grow and reproduce (Bugni and Ireland 2004), and lend themselves to facile culturing. From screening 16 endophytes isolated from five seagrasses and six marine algae found in the Bay of Bengal (southern India), we determined that four MDF from this group secreted the highest levels of $\beta$ xylosidase: Trichoderma harzianum (brown alga host: Sargassum wightii), Aspergillus terreus (seagrass host: Cymodocea serrulata), Gonatophragmium mori (seagrass host: Thalassia sp.) and Curvularia tuberculata (seagrass host: Syringodium sp.) (Thirunavukkarasu et al. 2015). (Note: Although brown algae are not members of the plant kingdom, we use here the term "endophyte" for the symptomless fungal endosymbiont of Sargassum wightii.) Interestingly, T. harzianum, which secreted the 
highest levels of xylanase and xylosidase from the abovementioned MDF group, could tolerate $1.2 \mathrm{M} \mathrm{NaCl}$ in the growth medium and elaborate xylanolytic enzymes in response to increasing salt concentrations (Thirunavukkarasu et al. 2015). Based on the hypothesis that salt tolerance might help identify MDF candidates that secrete ILresistant enzymes, we first sought to characterize the xylosidase(s) in the secretomes of T. harzianum, A. terreus, G. mori or C. tuberculata grown on xylan as the carbon substrate.

Given the success of 1,3-dialkylimidazolium ILs in dissolving crystalline cellulose (Liu et al. 2012; Peleteiro et al. 2015; Wahlstrom and Suurnakki 2015), we focused on IL tolerance with this genre (Scheme 1). We used p-nitrophenyl- $\beta$-D-xyloside (pNP-Xyl) as the substrate for our initial assays, and subsequently validated our findings on IL tolerance using xylobiose as substrate. The hydrolysis of xylan by xylanase generates xylobiose (X2) and xylotriose (X3) at high concentrations, and other longer oligosaccharides (X4 and above) at lower concentrations; after prolonged incubations, xylobiose, however, becomes the major product (for example, see Chawchart et al. 2014). Xylobiose in turn is cleaved further to xylose through the action of a $\beta$-xylosidase.

\section{Effect of $\mathrm{NaCl}$ and ionic liquids on $\beta$-xylosidase activity in different MDF secretomes}

Increasing $\mathrm{NaCl}$ from 0 to 0.6 or $1.2 \mathrm{M}$ in a 2-h assay had no significant effect on the xylosidase activity present in the secretomes of $T$. harzianum, A. terreus, G. mori or $C$. tuberculata (Fig. 1a). The plant/algal hosts of these MDF live in oceanic salt concentration of $\sim 0.6 \mathrm{M}$. Next, we tested the effect of EMIM-DMP as a representative of the imidazolium ILs (Fig. 1b). In contrast to our findings with $\mathrm{NaCl}$, only $\mathrm{T}$. harzianum and $A$. terreus xylosidases showed robust activity in the presence of $0.6 \mathrm{M}[10 \%(\mathrm{w} / \mathrm{v})]$ or even $1.2 \mathrm{M}[20 \%(\mathrm{w} / \mathrm{v})]$ EMIM-DMP in the assay (Fig. 2B). Because the $\beta$-xylosidase specific activity in the $T$. harzianum secretome was three-fold higher than that in the $A$. terreus secretome, we decided to study the former in depth. 
Effect of varying the anions in EMIM-based ILs on T. harzianum $\beta$-xylosidase activity

We reported earlier that addition of $1.5 \%(\mathrm{w} / \mathrm{v}) \mathrm{NaCl}$ in the growth medium led to a $~ 3-$ fold increase in the secreted xylosidase activity (Thirunavukkarasu et al. 2015), inspiring the use of secretomes obtained after growth in the presence of $\mathrm{NaCl}$. In our assays containing $10 \mathrm{mM}$ pNP- $\beta$-D-Xyl, we noticed that the $\beta$-xylosidase specific activity in Tha S+ was reproducibly $\sim 8$-fold higher than that in Tha S- (Fig. 3); our earlier finding of a 3-fold increase in Tha S+ compared to Tha S- was based on assays with $3 \mathrm{mM}$ pNP- $\beta$ D-Xyl, which was likely sub-optimal for maximum activity. Both the Tha S- and Tha S+ extracts retained $83 \pm 0.2 \%$ and $72 \pm 0.2 \%$ activity in 1.2 M EMIM-DMP, respectively, compared to the control where no IL was present. Similarities in the tolerance of Tha Sand Tha S+ to EMIM-DMP (and to the other ILs tested, see below) suggests that the same protein(s) likely accounts for the xylosidase activity in these secretomes (see below, Fig. 5).

Since ILs with strongly basic anions dissolve LCB (Karatzos et al. 2012), we sought to compare the effect of EMIM-DMP, EMIM-Cl and EMIM-Ac. Increasing the IL concentration from 0 to $1.2 \mathrm{M}$ resulted in $72 \pm 0.2 \%, 53 \pm 0 \%$ and $65 \pm 0.7 \%$ retention of the xylosidase activity in EMIM-DMP, EMIM-CI and EMIM-Ac, respectively. Similar trends were observed in Tha S- and Tha S+ (data not shown). The lower inhibition with EMIM-Ac relative to EMIM-Cl might be attributable to the lower viscosity of EMIM-Ac compared to EMIM-CI (Fendt et al. 2011).

\section{Effect of EMIM-DMP on T. harzianum xylosidase activity during prolonged incubation with pNP-Xyl and xylobiose}

Because longer half-lives of enzymes in the presence of ionic liquids will reduce the number of enzyme loadings during industrial bioprocessing, we investigated the xylosidase activity in Tha S- and Tha S+ during a 72-h and $48-\mathrm{h}$ time-course at $37^{\circ} \mathrm{C}$, respectively. Both the Tha S- and Tha S+ extracts exhibited $77 \pm 0.1 \%$ and $74 \pm 0.1 \%$ of their original activity in the presence of $0.6 \mathrm{M}$ EMIM-DMP, respectively. Even in the 
presence of 1.2 M EMIM-DMP, Tha S- and Tha S+ secretomes retained $53 \pm 0.1 \%$ and $44 \pm 0.1 \%$, respectively, of the initial xylosidase activity (Fig. 3 ).

We then assayed at $37^{\circ} \mathrm{C}$ the xylosidase activity of Tha $\mathrm{S}+$ using xylobiose (X2) as the substrate in the absence or presence of 0.6 or $1.2 \mathrm{M}$ EMIM-DMP. We used the DNS-based assay to determine the reducing sugar generated by xylosidase action on these substrates. Because the DNS reactivity with reducing sugars is influenced by ILs, we first obtained standard curves for xylose, X2 and X3 in the presence of 0.6 or $1.2 \mathrm{M}$ EMIM-DMP, and applied correction factors while assessing the activity in the presence of EMIM-DMP (see Materials and Methods for details). Indeed, we observed tolerance to EMIM-DMP with $X 2$, in fact greater than that observed with pNP- $\beta-D-X y l$ (Fig. 4); there was retention of $85 \%$ activity after a $9-\mathrm{h}$ incubation in the presence of $1.2 \mathrm{M}$ EMIM-DMP, and remarkably, 77\% activity after a 48-h incubation. We also found IL tolerance with X3 as the substrate, although our assays were performed for a shorter 2h period (data not shown).

\section{Characterization of $\beta$-xylosidase(s) in the T. harzianum secretome}

Next, we sought to characterize the $\beta$-xylosidase(s) in Tha $S$ - and Tha $S+$ crude secretomes. SDS-PAGE analysis using a 12\% NuPAGE pre-cast gel (Thermo Fisher) revealed that there was at least one protein $(\sim 100 \mathrm{kDa})$ whose levels increased severalfold upon inclusion of salt in the growth media and two other polypeptides ( 60 and 150 $\mathrm{kDa}$ ) that show less pronounced increases (Fig. 5a). To identify the number and approximate size of the $\beta$-xylosidase(s) in Tha $\mathrm{S}$ - and Tha $\mathrm{S}+$, we performed a zymogram analysis using 4-MU- $\beta-D-X y l$ as the substrate. Two proteins with $\beta$ xylosidase activity were reproducibly identified in both Tha S- and Tha S+ secretomes. Moreover, the activities displayed the expected trend of several-fold increased activity in the Tha S+ secretome compared to the Tha S- counterpart (Fig. 5b). It is difficult, however, to either draw firm conclusions on molecular mass from the native zymogram gel or make meaningful comparisons to the separate SDS-PAGE analysis of the same samples. Nevertheless, the weaker of the two activities migrates slower than and 
proximal to the BSA monomer while the stronger activity migrates slower than the BSA dimer (Fig. 5b).

Isolation and characterization of $\beta$-xylosidases from various filamentous fungi have revealed that these enzymes typically belong to $\mathrm{GH}$ families 3, 43 and 54, and could function as monomers, dimers or trimers (Knob et al. 2010). While the two polypeptides in Tha S- and S+ that display $\beta$-xylosidase activity (Fig. 5b) may correspond to either two distinct monomeric variants or two different oligomeric forms of a single species, the remarkable IL tolerance that we observed (Figs. 3 and 4 ) is attributable to one or two $\beta$ xylosidases and not a large suite of enzymes.

\section{DISCUSSION}

Our finding of IL-tolerant, long-lived $\beta$-xylosidase(s) resulted from our efforts to isolate MDF associated with plants/algae of the less-studied marine habitat and to assess the ability of these fungi to utilize xylan. While the Xyl- $\beta(1 \rightarrow 4)-X y l$ repeating unit makes up the polymer backbone, this core is decorated with galactosyl, glucuronyl and arabinofuranosyl substituents, which in turn form ester-based crosslinks with different hydroxycinnamic acids in lignin (Carpita 1996). Thus, the complete breakdown of hemicellulose requires xylanases and xylosidases, as well as galactosidases, glucuronidases, arabinosidases and acetyl/phenolic esterases (Kulkarni et al. 1999; Sunna and Antranikian 1997). Targeted bio-prospecting efforts of the type described should help build a complete IL-tolerant hemi-cellulolytic biocatalytic repertoire, especially if they can be generated economically from native sources or recombinant methods.

We consider the factors that have been reported to contribute to strong or weak IL tolerance of other enzymes, and draw from these insights to provide context for our results. First, there are precedents of even 5-fold activation of a cellulase in the presence of 0.6 M IL, and 2-fold in the presence of the same molarity of $\mathrm{NaCl}$ (Gladden et al. 2014). Thus, part of the tolerance was attributed to the requirement of salt for 
optimal activity. This reasoning is unlikely to apply to the $T$. harzianum $\beta$-xylosidase whose activity is the same in the absence or presence of $\mathrm{NaCl}$ (Fig. 1a). Second, changes in ionic strength and viscosity (modulated by altering $\mathrm{NaCl}$ and PEG, respectively) alone elicited a sharp decrease in the activity of a commercial cellulase, albeit not as pronounced as those in the presence of an IL (Engel et al. 2010). Our finding that $1.2 \mathrm{M} \mathrm{IL}$ but not $1.2 \mathrm{M} \mathrm{NaCl}$ (Fig. 1) was inhibitory to the T. harzianum $\beta$ xylosidase(s) rules out ionic strength as a key factor, although breaching specific viscosity thresholds are likely critical given the higher potency of the viscous EMIM-Cl compared to EMIM-Ac (Fig. 2). Third, while ILs could disrupt intra-molecular hydrogen bonding in enzymes and alter stability ( $\mathrm{Li}$ et al. 2013), they can also directly impact function. For example, kinetic and molecular docking studies revealed that ILs compete with the substrate for the active site of xylanases (Anbarasan et al. 2017; Chawachart et al. 2014). While there was no effect on the $V_{\max }$ of a xylanase from Thermoascus aurantiacus (a thermophilic ascomycetous fungus), addition of 15\% EMIM-Ac (or $\sim 0.9 \mathrm{M}$ ) led to a 3.5-fold increased $\mathrm{K}_{\mathrm{m}}$ for xylan (Chawachart et al. 2014). Indeed, we observed that the inhibitory potency of $1.2 \mathrm{M}$ EMIM-DMP towards T. harzianum $\beta$ xylosidase(s) was much lower at higher substrate concentrations (comparison of 3.33

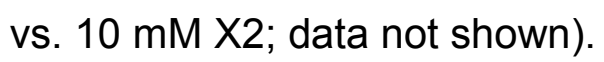

Anbarasan et al. (2017) recently concluded based on comparative analyses of different bacterial and fungal xylanases that there is a correlation between high affinity for substrate and lower susceptibility to inhibition by IL. The increased potency of IL with pNP-Xyl as the substrate compared to X2 (Figs. 3 and 4) suggests that similar factors may be at play with the $T$. harzianum $\beta$-xylosidase(s). Additional $\mathrm{H}$-bonding interactions with $\mathrm{X} 2$ are likely to protect against the detrimental effects of ILs. Establishing the role of active site topology and substrate interactions in IL tolerance will require high-resolution structures of xylosidase-substrate and $\mathrm{IL}$ complexes. We also point to the pitfall associated with an over-reliance on artificial substrates in initial screens.

Characterization of the IL tolerance of cellulases identified from different metagenomic studies suggests a strong correlation between thermostability and IL 
tolerance (Gladden et al. 2014; Ilmberger et al. 2012). Investigations of a thermophilic switchgrass-adapted microbial community (Gladden et al. 2014) led to the finding that enzymes with temperature optima greater than $70^{\circ} \mathrm{C}$ retain $80 \%$ activity even in the presence of 20 to $40 \%(\mathrm{v} / \mathrm{v})$ of EMIM-Ac during incubations lasting 15 to $60 \mathrm{~min}$ over a wide range of temperatures. Similarly, $T$. aurantiacus xylanase displayed nearly twothirds activity in $25 \%$ EMIM-Ac at $60^{\circ} \mathrm{C}$, where the enzyme has a half-life of $\sim 100 \mathrm{~h}$ (Chawachart et al. 2014). Despite the strong precedent for the linkage between thermostability and IL tolerance, our findings on the mesophilic T. harzianum $\beta$ xylosidase(s) suggests that the bioprospecting dragnet for identification of new ILtolerant LCB-degrading enzymes should include the marine habitat, including hydrothermal vents (Burgaud et al. 2009). Given the diversity and heterogeneous nature of LCB in plants of various lineages, having a palette of IL-tolerant cell-wall degrading enzymes from wide-ranging sources will help augment the limited repertoire of commercial cellulase and hemi-cellulase cocktails.

\section{ACKNOWLEDGEMENTS}

We thank Dr. N. Thirunavukkarasu (VINSTROM, INDIA) for his kind assistance with preparation of secretomes used in this study. We are grateful to Dr. Teddy Ezeji (OARDC/OSU) for the gift of birch wood xylan. We thank the Center for Applied Plant Sciences (CAPS) at The Ohio State University for supporting this research. AZ and SYT are indebted to NSF REU grant DBI-1062144 and CAPS, respectively, for funding.

\section{REFERENCES}

Anbarasan, S., Wahlstrom, R., Hummel, M., Ojamo, H., Sixta, H., and Turunen, O., 2017. High stability and low competitive inhibition of thermophilic Thermopolyspora flexuosa GH10 xylanase in biomass-dissolving ionic liquids. Appl Microbiol Biotechnol 101(4): 1487-1498. doi: 10.1007/s00253-016-7922-9.

Beckham, G.T., Dai, Z., Matthews, J.F., Momany, M., Payne, C.M., Adney, W.S., Baker, S.E., and Himmel, M.E., 2012. Harnessing glycosylation to improve cellulase activity. Curr Opin Biotechnol 23(3): 338-345. doi: 10.1016/j.copbio.2011.11.030.

Bugni, T.S., and Ireland, C.M., 2004. Marine-derived fungi: a chemically and biologically diverse group of microorganisms. Nat Prod Rep 21(1): 143-163. doi: 10.1039/b301926h. 
Burgaud, G., Le Calvez, T., Arzur, D., Vandenkoornhuyse, P., and Barbier, G., 2009. Diversity of culturable marine filamentous fungi from deep-sea hydrothermal vents. Environ Microbiol 11(6): 1588-1600. doi: 10.1111/j.1462-2920.2009.01886.x.

Carpita, N.C., 1996. Structure and biogenesis of the cell walls of grasses. Annu Rev Plant Physiol Plant Mol Biol 47: 445-476. doi: 10.1146/annurev.arplant.47.1.445.

Chawachart, N., Anbarasan, S., Turunen, S., Li, H., Khanongnuch, C., Hummel, M., Sixta, H., Granstrom, T., Lumyong, S., and Turunen, O., 2014. Thermal behaviour and tolerance to ionic liquid [emim]OAc in GH10 xylanase from Thermoascus aurantiacus SL16W. Extremophiles 18(6): 1023-1034. doi: 10.1007/s00792-014-0679-0.

Cord-Landwehr, S., Melcher, R.L., Kolkenbrock, S., and Moerschbacher, B.M., 2016. A chitin deacetylase from the endophytic fungus Pestalotiopsis sp. efficiently inactivates the elicitor activity of chitin oligomers in rice cells. Sci Rep 6: 38018. doi: 10.1038/srep38018.

Correa, R.C.G., Rhoden, S.A., Mota, T.R., Azevedo, J.L., Pamphile, J.A., de Souza, C.G.M., Polizeli, M.D.T.D., Bracht, A., and Peralta, R.M., 2014. Endophytic fungi: expanding the arsenal of industrial enzyme producers. J Ind Microbiol Biotechnol 41(10): 1467-1478. doi: 10.1007/s10295-014-1496-2.

Dadi, A.P., Varanasi, S., and Schall, C.A., 2006. Enhancement of cellulose saccharification kinetics using an ionic liquid pretreatment step. Biotechnol Bioeng 95(5): 904-910. doi: 10.1002/bit.21047.

Datta, S., Holmes, B., Park, J.I., Chen, Z.W., Dibble, D.C., Hadi, M., Blanch, H.W., Simmons, B.A., and Sapra, R., 2010. Ionic liquid tolerant hyperthermophilic cellulases for biomass pretreatment and hydrolysis. Green Chem 12(2): 338-345. doi: 10.1039/b916564a.

Davies, P., Morvan, C., Sire, O., and Baley, C., 2007. Structure and properties of fibres from sea-grass (Zostera marina). J Mater Sci 42(13): 4850-4857. doi: 10.1007/s10853-006-0546-1.

Engel, P., Mladenov, R., Wulfhorst, H., Jager, G., and Spiess, A.C., 2010. Point by point analysis: how ionic liquid affects the enzymatic hydrolysis of native and modified cellulose. Green Chem 12(11): 1959-1966. doi: 10.1039/c0gc00135j.

Fendt, S., Padmanabhan, S., Blanch, H.W., and Prausnitz, J.M., 2011. Viscosities of acetate or chloride-based ionic liquids and some of their mixtures with water or other common solvents. J Chem Eng Data 56(1): 31-34. doi: 10.1021/je1007235.

Froschauer, C., Hummel, M., lakovlev, M., Roselli, A., Schottenberger, H., and Sixta, H., 2013. Separation of hemicellulose and cellulose from wood pulp by means of ionic liquid/cosolvent systems. Biomacromolecules 14(6): 1741-1750. doi: 10.1021/bm400106h. 
Gladden, J.M., Allgaier, M., Miller, C.S., Hazen, T.C., VanderGheynst, J.S., Hugenholtz, P., Simmons, B.A., and Singer, S.W., 2011. Glycoside hydrolase activities of thermophilic bacterial consortia adapted to switchgrass. Appl Environ Microb 77(16): 5804-5812. doi: 10.1128/Aem.00032-11.

Gladden, J.M., Park, J.I., Bergmann, J., Reyes-Ortiz, V., D'haeseleer, P., Quirino, B.F., Sale, K.L., Simmons, B.A., and Singer, S.W., 2014. Discovery and characterization of ionic liquidtolerant thermophilic cellulases from a switchgrass-adapted microbial community. Biotechnology for Biofuels 7. doi: Artn 1510.1186/1754-6834-7-15.

Himmel, M.E., Ding, S.Y., Johnson, D.K., Adney, W.S., Nimlos, M.R., Brady, J.W., and Foust, T.D., 2007. Biomass recalcitrance: engineering plants and enzymes for biofuels production. Science 315(5813): 804-807. doi: 10.1126/science.1137016.

Ilmberger, N., Meske, D., Juergensen, J., Schulte, M., Barthen, P., Rabausch, U., Angelov, A., Mientus, M., Liebl, W., Schmitz, R.A., and Streit, W.R., 2012. Metagenomic cellulases highly tolerant towards the presence of ionic liquids-linking thermostability and halotolerance. Appl Microbiol Biot 95(1): 135-146. doi: 10.1007/s00253-011-3732-2.

Ilmberger, N., Pottkamper, J., and Streit, W.R. 2013., Cellulases in ionic liquids-The long term stability of Aspergillus sp cellulase. Catalysts 3(2): 584-587. doi: 10.3390/catal3020584.

Kamiya, N., Matsushita, Y., Hanaki, M., Nakashima, K., Narita, M., Goto, M., and Takahashi, H., 2008. Enzymatic in situ saccharification of cellulose in aqueous-ionic liquid media. Biotechnol Lett 30(6): 1037-1040. doi: 10.1007/s10529-008-9638-0.

Karatzos, S.K., Edye, L.A., and Doherty, W.O., 2012. Sugarcane bagasse pretreatment using three imidazolium-based ionic liquids; mass balances and enzyme kinetics. Biotechnol Biofuels 5(1): 62. doi: 10.1186/1754-6834-5-62.

Knob, A., Terrasan, C.R.F., and Carmona, E.C., 2010. Beta-Xylosidases from filamentous fungi: an overview. World J Microb Biot 26(3): 389-407. doi: 10.1007/s11274-009-0190-4.

Kulkarni, N., Shendye, A., and Rao, M., 1999. Molecular and biotechnological aspects of xylanases. Fems Microbiol Rev 23(4): 411-456.

Li, H., Kankaanpaa, A., Xiong, H.R., Hummel, M., Sixta, H., Ojamo, H., and Turunen, O., 2013. Thermostabilization of extremophilic Dictyoglomus thermophilum $\mathrm{GH} 11$ xylanase by an Nterminal disulfide bridge and the effect of ionic liquid [emirp]OAc on the enzymatic performance. Enzyme Microb Tech 53(6-7): 414-419. doi: 10.1016/j.enzmictec.2013.09.004.

Liu, C.Z., Wang, F., Stiles, A.R., and Guo, C., 2012. Ionic liquids for biofuel production: Opportunities and challenges. Appl Energ 92: 406-414. doi: 10.1016/j.apenergy.2011.11.031. 
Nakamura, A., Miyafuji, H., Saka, S., Mori, M., and Takahashi, H. 2010., Recovery of cellulose and xylan liquefied in ionic liquids by precipitation in anti-solvents. Holzforschung 64(1): 77-79. doi: 10.1515/Hf.2010.004.

Park, J.I., Steen, E.J., Burd, H., Evans, S.S., Redding-Johnson, A.M., Batth, T., Benke, P.I., D'haeseleer, P., Sun, N., Sale, K.L., Keasling, J.D., Lee, T.S., Petzold, C.J., Mukhopadhyay, A., Singer, S.W., Simmons, B.A., and Gladden, J.M., 2012. A Thermophilic Ionic Liquid-Tolerant Cellulase Cocktail for the Production of Cellulosic Biofuels. PLOS One 7(5). doi: ARTN e37010 10.1371/journal.pone.0037010.

Peleteiro, S., Rivas, S., Alonso, J.L., Santos, V., and Parajo, J.C. 2015. Utilization of ionic liquids in lignocellulose biorefineries as agents for separation, derivatization, fractionation, or pretreatment. J Agr Food Chem 63(37): 8093-8102. doi: 10.1021/acs.jafc.5b03461.

Prakash, C.P., Thirumalai, E., Rajulu, M.B.G., Thirunavukkarasu, N., and Suryanarayanan, T.S., 2015. Ecology and diversity of leaf litter fungi during early-stage decomposition in a seasonally dry tropical forest. Fungal Ecol 17: 103-113. doi: 10.1016/j.funeco.2015.05.004.

Qing, Q., and Wyman, C.E., 2011. Supplementation with xylanase and beta-xylosidase to reduce xylo-oligomer and xylan inhibition of enzymatic hydrolysis of cellulose and pretreated corn stover. Biotechnol Biofuels 4(1): 18. doi: 10.1186/1754-6834-4-18.

Qing, Q., Yang, B., and Wyman, C.E., 2010. Xylooligomers are strong inhibitors of cellulose hydrolysis by enzymes. Bioresour Technol 101(24): 9624-9630. doi: 10.1016/j.biortech.2010.06.137.

Robl, D., Delabona, P.D., Mergel, C.M., Rojas, J.D., Costa, P.D., Pimentel, I.C., Vicente, V.A., Pradella, J.G.D., and Padilla, G., 2013. The capability of endophytic fungi for production of hemicellulases and related enzymes. BMC Biotechnol 13. doi: Artn 9410.1186/1472-6750-1394.

Shi, J., Gladden, J.M., Sathitsuksanoh, N., Kambam, P., Sandoval, L., Mitra, D., Zhang, S., George, A., Singer, S.W., Simmons, B.A., and Singh, S., 2013. One-pot ionic liquid pretreatment and saccharification of switchgrass. Green Chem 15(9): 2579-2589. doi: 10.1039/c3gc40545a.

Sunna, A., and Antranikian, G., 1997. Xylanolytic enzymes from fungi and bacteria. Crit Rev Biotechnol 17(1): 39-67. doi: 10.3109/07388559709146606.

Suryanarayanan, T.S., Thirunavukkarasu, N., Govindarajulu, M.B., and Gopalan, V., 2012. Fungal endophytes: an untapped source of biocatalysts. Fungal Divers 54(1): 19-30. doi: 10.1007/s13225-012-0168-7. 
Swatloski, R.P., Spear, S.K., Holbrey, J.D., and Rogers, R.D., 2002. Dissolution of cellose with ionic liquids. J Am Chem Soc 124(18): 4974-4975. doi: 10.1021/ja025790m.

Thirunavukkarasu, N., Jahnes, B., Broadstock, A., Rajulu, M.B.G., Murali, T.S., Gopalan, V., and Suryanarayanan, T.S., 2015. Screening marine-derived endophytic fungi for xylandegrading enzymes. Curr Sci India 109(1): 112-120.

Turner, M.B., Spear, S.K., Huddleston, J.G., Holbrey, J.D., and Rogers, R.D., 2003. lonic liquid salt-induced inactivation and unfolding of cellulase from Trichoderma reesei. Green Chem 5(4): 443-447. doi: 10.1039/b302570e.

Vancov, T., Alston, A.S., Brown, T., and Mclntosh, S., 2012. Use of ionic liquids in converting lignocellulosic material to biofuels. Renew Energ 45: 1-6. doi: 10.1016/j.renene.2012.02.033.

Wahlstrom, R.M., and Suurnakki, A., 2015. Enzymatic hydrolysis of lignocellulosic polysaccharides in the presence of ionic liquids. Green Chem 17(2): 694-714. doi: 10.1039/c4gc01649a.

Wilson, D.B., 2009. Cellulases and biofuels. Curr Opin Biotech 20(3): 295-299. doi: 10.1016/j.copbio.2009.05.007.

Zhang, T., Datta, S., Eichler, J., Ivanova, N., Axen, S.D., Kerfeld, C.A., Chen, F., Kyrpides, N., Hugenholtz, P., Cheng, J.F., Sale, K.L., Simmons, B., and Rubin, E.,, 2011. Identification of a haloalkaliphilic and thermostable cellulase with improved ionic liquid tolerance. Green Chem 13(8): 2083-2090. doi: 10.1039/c1gc15193b. 


\section{FIGURE CAPTIONS}

Fig. 1. Comparison of xylosidase relative specific activities in the presence of (a) $\mathrm{NaCl}$ and (b) EMIM-DMP. Secreted xylosidase activities from Trichoderma harzianum, Aspergillus terreus, Gonatophragmium mori and Curvularia tuberculata were determined at $37^{\circ} \mathrm{C}$ in the presence of $0,0.6$ or $1.2 \mathrm{M} \mathrm{NaCl}$ (a) and EMIM-DMP (b). To compare the four endophytes, xylosidase activities were normalized using as reference T. harzianum activity observed in the absence of any additive (see Materials and Methods). The error bars represent the standard deviation of the means determined from three independent experiments.

Fig. 2. Effect of varying the anion in the EMIM-based ionic liquids on the T. harzianum xylosidase activity. The secretomes obtained from $T$. harzianum grown in the absence or presence of $1.5 \%(\mathrm{w} / \mathrm{v}) \mathrm{NaCl}$ are labeled as Tha S- or Tha S+, respectively. While Tha S- was assayed in the presence of $0,0.6,0.9$ or 1.2M EMIM-DMP, Tha $\mathrm{S}+$ was additionally assayed with either EMIM-acetate or EMIM-chloride. Relative activities were calculated by normalization using as reference Tha S- or Tha S+ activity observed in the absence of any additive (see Materials and Methods). The error bars represent the standard deviation of the means determined from at least three independent experiments.

Fig. 3. Effect of EMIM-DMP on Tha S- (a) or Tha $S+$ (b) xylosidase stability after prolonged incubation at $37^{\circ} \mathrm{C}$. Xylosidase activities of Tha S- or Tha S+ secretomes were assayed in the presence of $0,0.6$ or $1.2 \mathrm{M}$ EMIM-DMP for 72 (a) or $48 \mathrm{~h}$ (b), respectively. Initial velocities were determined from time-course experiments and used to calculate the specific activity (left panels depicts representative plots); data from three independent initial velocity measurements were used to calculate the mean and standard deviation (right panels). In each case, the respective $T$. harzianum secretome assayed without any additives served as the reference for normalization (see Materials and Methods).

Fig. 4. Xylosidase activity of Tha S+ on xylobiose in the absence or presence of EMIMDMP. Initial velocities were determined from 9-h time-course studies and then used to 
calculate the specific activity (left panel depicts representative plots of xylose formation as a function of time). Data from three independent time-course experiments were used to calculate the mean and standard deviation (right panel). In each case, Tha S+ secretome assayed without any additive served as the reference for normalization (see Materials and Methods).

Fig. 5. Identification of $\beta$-xylosidase(s) in the T. harzianum secretome. (a) SDS-PAGE analysis of Tha S- and Tha S+ crude secretomes using a 12\% NuPAGE Bis-Tris precast gel. (b) Zymogram analysis to detect $\beta$-xylosidase activity after $12 \%(\mathrm{w} / \mathrm{v})$ polyacrylamide native gel electrophoresis. In both panels: lane 1, size markers; lanes 2 and 3 correspond to $40 \mu \mathrm{g}$ of Tha S- and Tha S+ secretome protein, respectively. Size markers used in (a) were Precision Plus Protein Kaleidoscope pre-stained size markers (Biorad) and in (b) were Precision Plus Dual Color size markers (Biorad). Note that 66and 132-kDa standards in (b) correspond to monomeric and dimeric forms of bovine serum albumin (Pierce), which was pre-stained with Coomassie blue and electrophoresed on an adjacent lane (data not shown). Black dots signify proteins that are increased in the Tha S+ proteome compared to the Tha S- counterpart. 

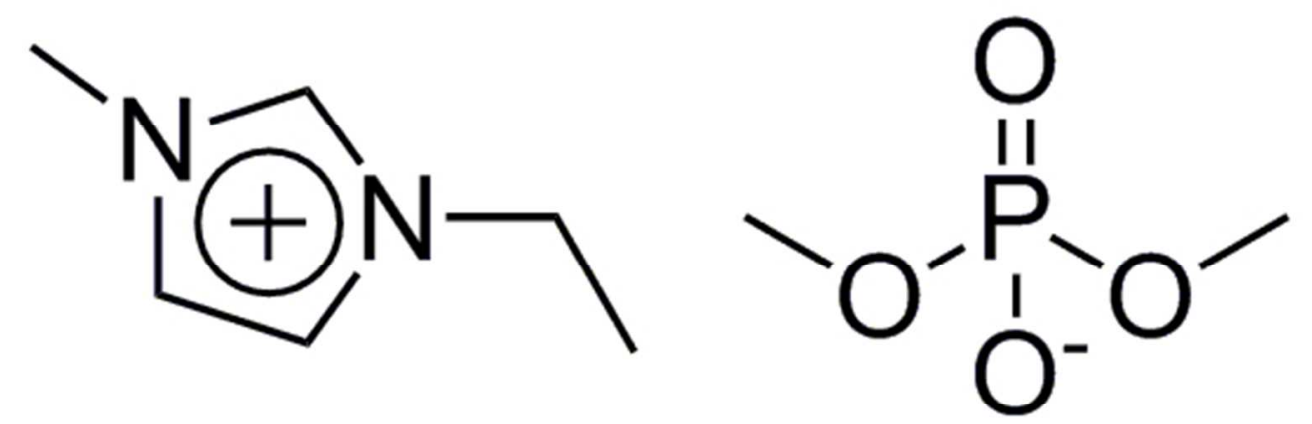

1-Ethyl-3-methylimidazolium dimethylphosphate

Scheme 1

$46 \times 20 \mathrm{~mm}(300 \times 300$ DPI $)$ 
a
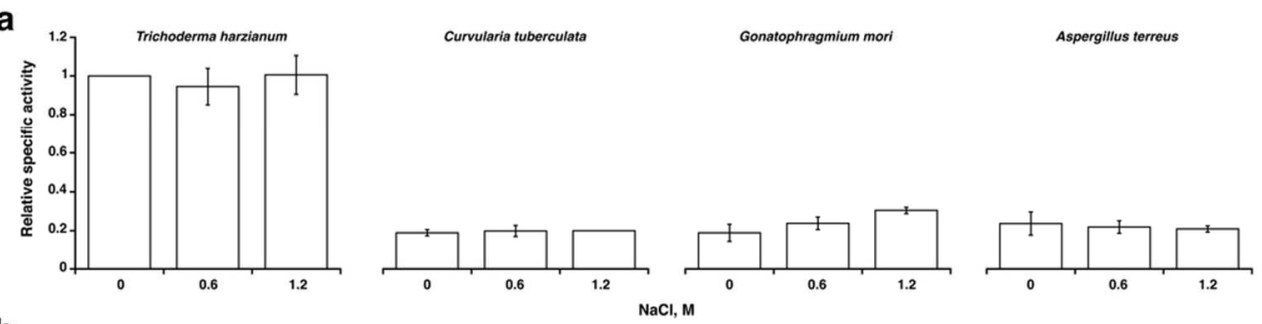

b
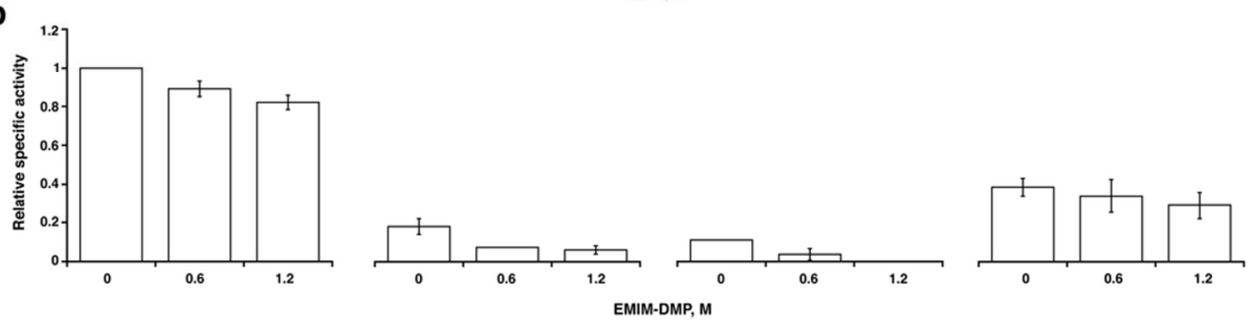

Figure 1. Comparison of xylosidase relative specific activities in the presence of (a) NaCl and (b) EMIM-DMP. Secreted xylosidase activities from Trichoderma harzianum, Aspergillus terreus, Gonatophragmium mori and Curvularia tuberculata were determined at $37^{\circ} \mathrm{C}$ in the presence of $0,0.6$ or $1.2 \mathrm{M} \mathrm{NaCl}$ (a) and EMIM-DMP (b). To compare the four endophytes, xylosidase activities were normalized using as reference T. harzianum activity observed in the absence of any additive (see Materials and Methods). The error bars represent the standard deviation of the means determined from three independent experiments.

$87 \times 44 \mathrm{~mm}(300 \times 300 \mathrm{DPI})$ 

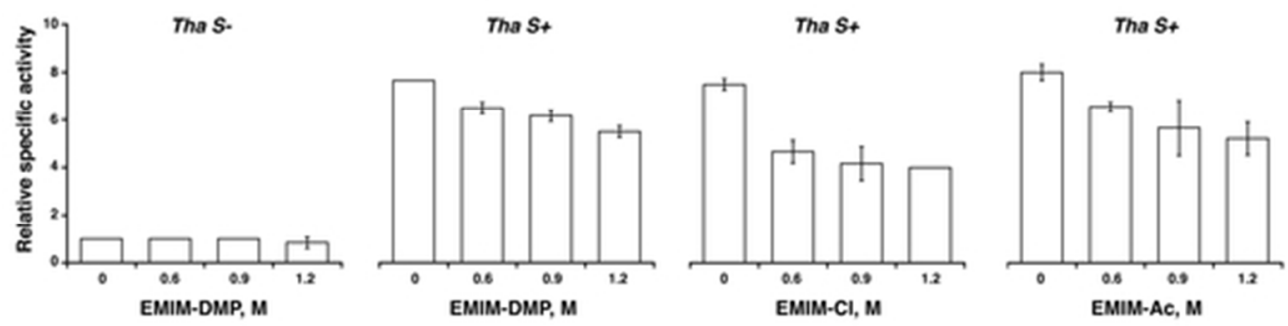

Figure 2. Effect of varying the anion in the EMIM-based ionic liquids on the T. harzianum xylosidase activity. The secretomes obtained from T. harzianum grown in the absence or presence of $1.5 \%(\mathrm{w} / \mathrm{v}) \mathrm{NaCl}$ are labeled as Tha S- or Tha S+, respectively. While Tha S- was assayed in the presence of $0,0.6,0.9$ or $1.2 \mathrm{M}$ EMIM-DMP, Tha S+ was additionally assayed with either EMIM-acetate or EMIM-chloride. Relative activities were calculated by normalization using as reference Tha S- or Tha S+ activity observed in the absence of any additive (see Materials and Methods). The error bars represent the standard deviation of the means determined from at least three independent experiments.

$45 \times 12 \mathrm{~mm}(300 \times 300$ DPI $)$ 

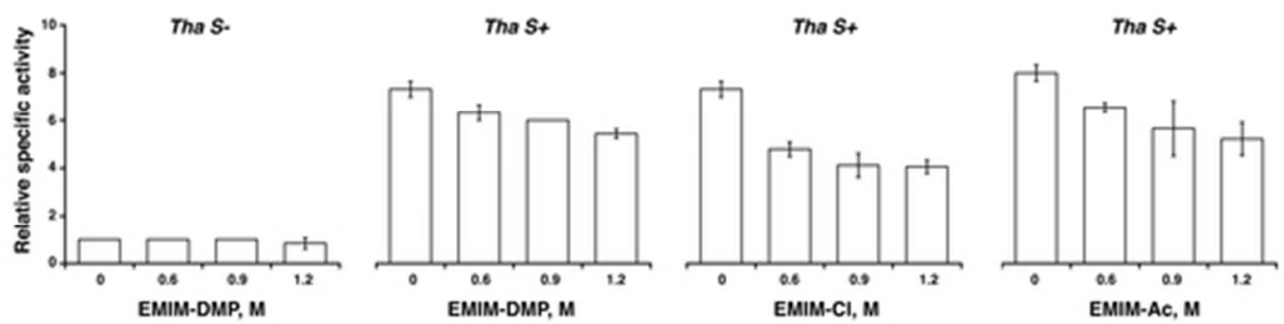

Figure 3. Effect of EMIM-DMP on Tha S- (a) or Tha S+ (b) xylosidase stability after prolonged incubation at $37^{\circ} \mathrm{C}$. Xylosidase activities of Tha S- or Tha S+ secretomes were assayed in the presence of $0,0.6$ or $1.2 \mathrm{M}$ EMIM-DMP for 72 (a) or $48 \mathrm{~h}$ (b), respectively. Initial velocities were determined from time-course experiments and used to calculate the specific activity (left panels depicts representative plots); data from three independent initial velocity measurements were used to calculate the mean and standard deviation (right panels). In each case, the respective T. harzianum secretome assayed without any additives served as the reference for normalization (see Materials and Methods).

$45 \times 12 \mathrm{~mm}(300 \times 300$ DPI $)$ 

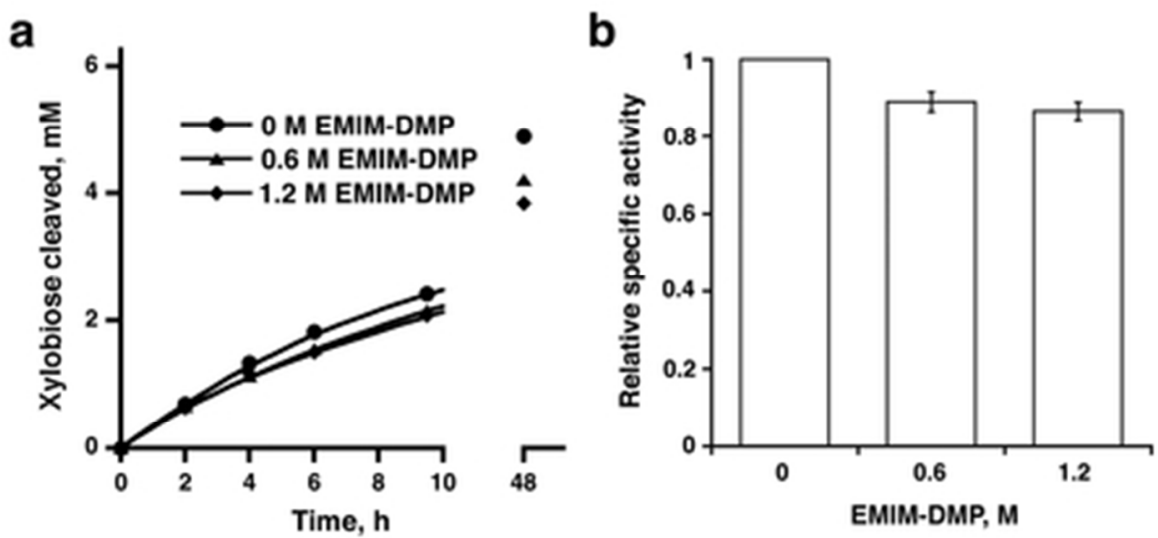

Figure 4. Xylosidase activity of Tha $\mathrm{S}+$ on xylobiose in the absence or presence of EMIM-DMP. Initial velocities were determined from 9 -h time-course studies and then used to calculate the specific activity (left panel depicts representative plots of xylose formation as a function of time). Data from three independent time-course experiments were used to calculate the mean and standard deviation (right panel). In each case, Tha S+ secretome assayed without any additive served as the reference for normalization (see Materials and Methods).

$39 \times 19 \mathrm{~mm}(300 \times 300$ DPI $)$ 


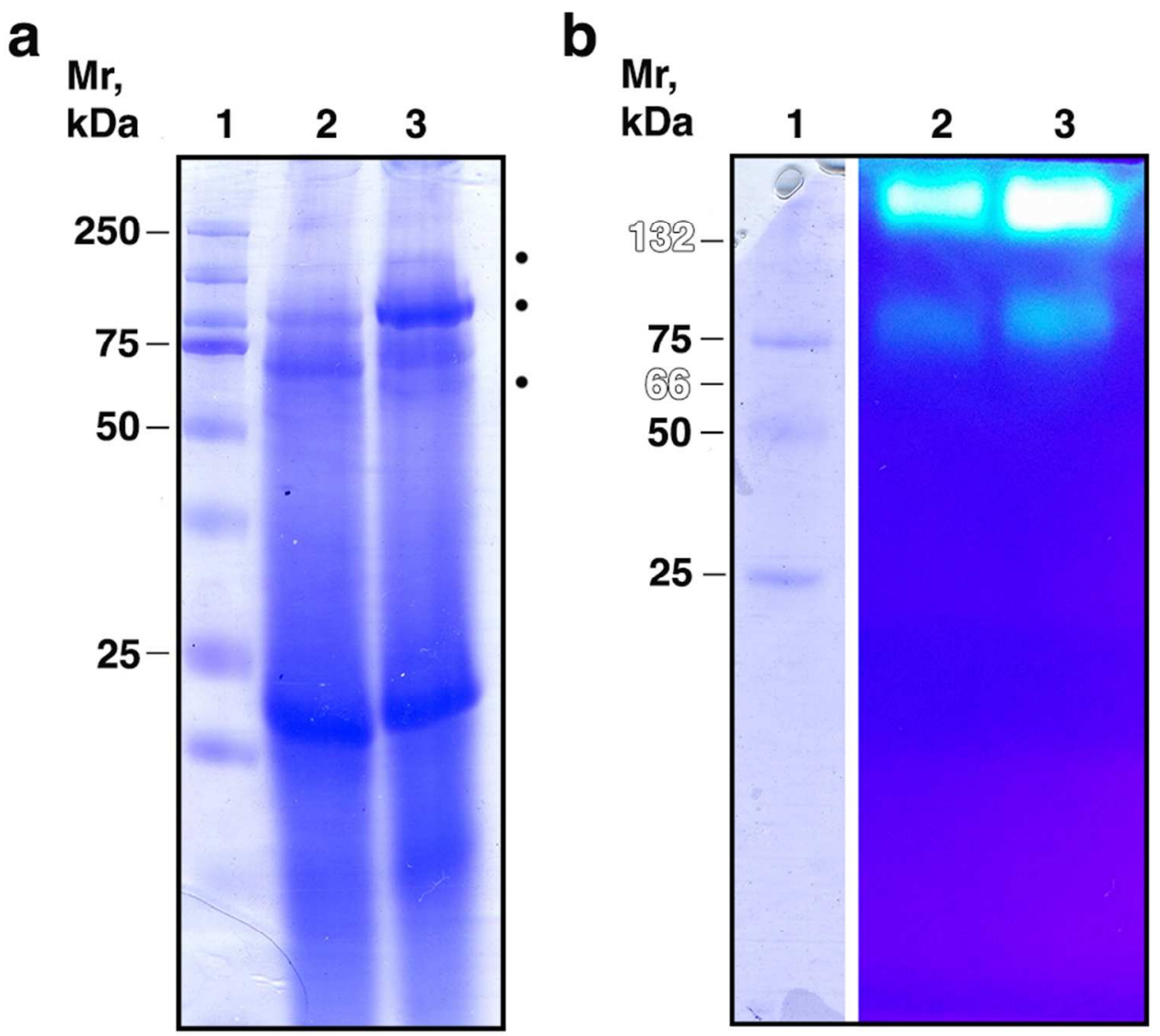

Fig. 5. Identification of $\beta$-xylosidase(s) in the T. harzianum secretome. (a) SDS-PAGE analysis of Tha S- and Tha S+ crude secretomes using a $12 \%$ NuPAGE Bis-Tris pre-cast gel. (b) Zymogram analysis to detect $\beta$ xylosidase activity after $12 \%(\mathrm{w} / \mathrm{v})$ polyacrylamide native gel electrophoresis. In both panels: lane 1 , size markers; lanes 2 and 3 correspond to $40 \mu \mathrm{g}$ of Tha S- and Tha S+ secretome protein, respectively. Size markers used in (a) were Precision Plus Protein Kaleidoscope pre-stained size markers (Biorad) and in (b) were Precision Plus Dual Color size markers (Biorad). Note that 66- and 132-kDa standards in (b) correspond to monomeric and dimeric forms of bovine serum albumin (Pierce), which was pre-stained with Coomassie blue and electrophoresed on an adjacent lane (data not shown). Black dots signify proteins that are increased in the Tha S+ proteome compared to the Tha S-counterpart.

$$
83 \times 74 \mathrm{~mm}(300 \times 300 \mathrm{DPI})
$$

